\title{
International Physics Masterclasses and Workshop on Particle Physics: Professional Development Tools for High School Teachers in São Paulo
}

\author{
Rodrigo Araújo' \\ Programa de Pós-Graduação Interunidades em Ensino de Ciências - USP \\ São Paulo, Brazil \\ E-mail: araujo.rodrigoeusp.br

\section{Valéria Silva Dias} \\ Instituto de Física - USP \\ São Paulo, Brazil \\ E-mail: vsdiaseif.usp.br
}

\begin{abstract}
Every year thousands of students from all around the world and their teachers take part in an outreach event developed by the International Particle Physics Outreach Group (IPPOG): The International Particle Physics Masterclasses - hands on particle physics. During this event, they engage with scientists, learn about particle physics and simulate the work of a high-energy physics scientist. In the city of São Paulo, Brazil, the SPRACE (São Paulo Research and Analysis Center) team locally organizes this event every year since 2008 . We studied how attending this event and a workshop on particle physics, also promoted by the SPRACE team, can help physics teachers to address particle physics in high school. To collect data, we used a questionnaire answered by the teachers at the end of the International Physics Masterclasses in March 2016. The conclusion was that attending these events, teachers are increasing their scientific knowledge, getting more confident and getting to know new materials and new ways to address particle physics in high school.
\end{abstract}

38th International Conference on High Energy Physics

3-10 August 2016

Chicago, USA 


\section{Introduction}

Research centers, laboratories and scientists from all around the world have been devoting time and resources to the divulgation of their scientific activities and its results. This very section of ICHEP 2016 (education and outreach) is a proof of this effort. Even so, Modern and Contemporary Physics (MCP), including high-energy physics, still seems very distant to high school students. Most physics curricula still address only the so-called classical physics, and even when MCP topics are included in the curricula, teaching these subjects has proved to be a challenge.

In Brazil, the official documents that guide the elaboration of high school curricula (PCN [1] and PCN+ [2]) emphasize the importance of learning MCP topics in high school. The physics curriculum for high school in the state of São Paulo, elaborated according to these documents, includes topics of particle physics among the subjects to be taught in the last year of high school. However, in practice, most teachers do not address these topics and the students are leaving school without learning anything about it.

Researches carried out to investigate the difficulties encountered by teachers to teach modern physics topics [3] point to deficiencies in teacher education and the lack of adequate teaching materials to teach these topics in high school as the main barriers faced by teachers. Often teachers have no contact with MCP topics during their education. Even when they do, it is fast and insufficient for future teachers to address these topics at school. It is also worth remembering that many physics teachers who work in Brazilian schools do not even have education in this area.

With a view to bringing high-energy physics to a larger audience, including high school students, we believe that outreach events can play an important role in providing scientific knowledge, ideas and resources to teachers, helping them to bring new subjects into the classroom.

In the city of São Paulo, the SPRACE (São Paulo Research and Analysis Center) team promote several education and outreach initiatives [4] involving particle physics, among which we highlight the SPRACE electronic game, the "Elementary Structure of Matter: A Poster in Every School" project, the local organization of the International Physics Masterclasses and the Workshop on Particle Physics. In this work, we analyze how two of these initiatives, the International Physics Masterclasses and the Particle Physics Workshop, have influenced the professional development of the attending teachers and are helping them to teach particle physics in high school.

\section{International Physics Masterclasses and Particle Physics Workshop}

The International Physics Masterclasses is a scientific outreach event promoted by IPPOG since 2005, inspired by a similar event organized by Roger Barlow in the United Kingdom [5]. The main idea of the event is to bring high school students and their teachers to universities and research centers to interact with scientists who work on high energy physics in collaboration with CERN. Participants attend lectures on particle accelerators and the standard model and perform an activity of real data analysis obtained in one of the four experiments that run at CERN (CMS, ALICE, ATLAS and LHCb). 
As the event occurs simultaneously in different locations around the world, at the end of the analysis activity the participants join a videoconference moderated by CERN scientists, so that the results are discussed in a similar way to what happens in an international scientific collaboration.

The SPRACE team organizes the International Physics Masterclasses at the Institute of Theoretical Physics (IFT) of the São Paulo State University (Unesp), in São Paulo, since 2008. The first edition had only two participating schools, but the success of the event made that number increase year by year. Since 2014 the participants are divided into two groups: an advanced group (one-day event), with schools whose students attend to preparatory lectures organized by their teachers in their school and a beginner group (two-day events), formed mostly by students who did not attend any prior preparation. In 2016, 209 students and 28 teachers from 22 schools attended to the event.

As many teachers who attended the first editions of Masterclasses presented a demand for more specific events, in 2012 the first Workshop on Particle Physics at UNESP was organized in the week preceding the Masterclasses of that year.

This first edition lasted four days. In the morning there were introductory lectures on particle physics, detectors, astrophysics, and LHC physics, followed by discussions. Afternoons were reserved for demonstrations and experiments (like determination of Planck's constant and observation of Brownian motion).

The second edition of the workshop took place in October 2015. This edition lasted only two days and had a different design from the previous edition. Among the eight presentations and discussions that occurred during the event, six were based on learning situations proposed by the state of São Paulo curriculum for physics. The topics addressed were the spectroscope, introduction to particle physics, cloud chamber construction, introduction to detectors and LHC physics, standard model (quarks) and particle transformations (decays, conservation laws, etc.). Participants also had the opportunity to play games whose theme is particle physics and one of them presented the project of an accelerator produced by high school students.

\section{Methodology}

In this work, we choose to investigate how the studied events can contribute to the teachers' professional development from their perceptions about the participation in these events. Thus, we consider a qualitative approach convenient, allowing us to "take into account experiences from the point of view of the informant" [6]. Our objective is to perceive and describe how the teachers who attended these events interpret and attribute meanings to their experiences, especially concerning their professional development.

To collect data, we used a questionnaire answered by the teachers at the end of the International Physics Masterclasses in March 2016. Answering the questionnaire was not mandatory and the choice of the moment to apply it took into account the proximity between this event and the second edition of the Workshop on Particle Physics.

The questionnaire contained ten questions about the teachers' pedagogical practices (regarding the teaching of particle physics), the difficulties in teaching particle physics, their expectations before the participation in both events and how attending these events can contribute to their practices. Sixteen teachers answered the questionnaires.

The data analysis was divided into three stages: 
1) Search for objective data about where teachers teach, their education, participation in the studied events, etc;

2) Categorization of the difficulties pointed out by teachers for the teaching of particle physics in high school and

3) Survey of the contributions of the events as pointed out by the teachers and comparison between these contributions and the difficulties previously categorized.

\section{Analysis and Results}

Eleven of the sixteen teachers who answered the questionnaire teach in state schools, four in private schools and only one teaches in a federal school. Six teachers (T05, T07, T08, T13, T14 and T16) were participating for the first time in the event. Teacher T12 had already participated in four editions and teachers T03 and T11, six editions each one. Four of the six teachers who had never attended the Masterclasses (T05, T07, T08 and T16) had already attended the Workshop on Particle Physics in the previous year. Thus, only T13 and T14 had never attended either the Masterclasses or the Workshop. Among those who had attended at least one previous edition of the Masterclasses, only T02 and T04 had not attended the Workshop.

The third item in the questionnaire was: "In your opinion, what are the major difficulties teachers face in including particle physics in the high school curriculum? Can you name some concrete examples?". The answers to this question led us to categorize the identified difficulties into three groups: deficiency in teachers' education, lack of proper teaching materials and lack of time due to the extension of the curriculum.

The excerpts below illustrate examples of these categories:

"Teachers have difficulties related to their education, since few have learned about particle physics at the college" (T9)

"I believe that this issue is not well addressed in teachers' education, which makes it very difficult for this subject to be taught" (T12)

"Materials for studying and teaching. The High School books do not address these topics" (T14)

"There are too many topics to address and the time is very short." (T4)

It is clear that those teachers who have never had contact with particle physics or other MCP topics will not be able to teach them unless they seek additional education to fill the gaps of their initial education. Similarly, those teachers who learned only the basics of these topics do not feel confident about this task. This lack of confidence can be seen in one of the answers to the question "What are your goals and/or expectations when attending the Masterclass?":

"I am interested in learning a little more in order to feel confident in working [this topic] with students" (T14) 
The teacher's confidence to teach a particular topic or develop a classroom activity is related to his or her self-efficacy belief. The teacher's personal self-efficacy, which is affected, among other factors, by his education [7], is related to his judgment about his own ability to succeed in a given task. According to Rocha and Ricardo [8], teachers' self-efficacy beliefs "influence their choices and make them choose to perform tasks in which they feel more confident and competent, as well as avoid those in which they do not feel that way". Applying this idea to the context of the present research, we can state that teachers who do not feel confident due to gaps in their education will probably not teach particle physics or other MCP topics.

Answering about the contributions of the events, teachers stated that attending both events resulted in benefits by means of new scientific and pedagogical knowledge, new ways to address these topics as well as material resources:

"... (I) had no idea of so many possibilities to address the content that will be worked with the students" (T1)

"I learned a lot; besides learning about particle physics, I also discovered new methods and instructional experiences from other teachers." (T17)

"[The workshop] approaches the teacher to the reality of current researches, providing elements to contextualize [particle physics in school]" (T9)

“... the material provided here, and some other teachers' ideas, facilitated my life" (T10)

"Many materials used in the workshop were important for the preparation of classes last year. [...]" (T3)

We believe that by saying that they have learned a lot and discovered new ways for addressing particle physics with their students, teachers evidences that participation in both events contributed to their professional development. In addition, the fact that they stated that the materials presented at the events were used later shows that this participation also helped to remedy another difficulty pointed out by the teachers: the lack of teaching materials that address these topics properly.

\section{Conclusions}

The analysis of the answers provided by teachers shown that they attribute educational and motivational meanings to the studied events. They try to fill some gaps in their initial education through theoretical and material instrumentation for particle physics teaching. The analysis also showed that these expectations are being met, besides evidencing that the instrumentalization for teaching and the increase of scientific knowledge had a motivational effect, possibly affecting the participants' self-efficacy beliefs. That is why we believe that these events have contributed to the professional development of attending teachers and can help to increase the reach of high-energy physics in schools. 
The studied events has also helped teachers to overcome two of the three main difficulties pointed out by themselves for teaching MCP topics in high school: the gaps in initial education and the lack of proper materials. Regarding the lack of time due to the extension of the curriculum, solving this problem depends on political and administrative actions that lead to a curricular remodeling.

On the limitations of this work, we can say that the data analyzed comprise only a part of the information collected and therefore a deepening of the research is necessary. In addition, we believe that the fact that teachers belong to a group that has already been willing to participate in the studied events (showing that they look for continuous education) may influence the results of the analysis.

In the future, we intend to deepen the analysis by using a greater amount of data, including new sources. However, we believe that the conclusions presented here may point out ways and raise questions for further research.

\section{References}

[1] Brasil, Ministério da Educação, Secretaria de Educação Média e Tecnológica. (1999) Parâmetros Curriculares Nacionais: ensino médio. Brasília: Ministério da Educação.

[2] Brasil, Secretaria de Educação Média e Tecnológica. (2002) PCN+ Ensino Médio: orientações educacionais complementares aos Parâmetros Curriculares Nacionais. Ciências da Natureza, Matemática e suas Tecnologias. Brasília: MEC, SEMTEC.

[3] Oliveira, F. F., Vianna, D. M., Gerbassi, R.S. (2007) Física moderna no ensino médio: o que dizem os professores. Revista Brasileira de Ensino de Física, 29(3).

[4] https://www.sprace.org.br/

[5] BARLOW, R. (2014). How the Particle Physics Masterclasses began. CERN Courier http://cerncourier.com/cws/article/cern/55890

[6] Bogdan, R., \& Biklen, S. K. (1997). Qualitative research for education. Boston: Allyn \& Bacon.

[7] Rocha, D. M.; Ricardo, E. C. (2011) Crenças de Autoeficácia e a Formação Docente em Física Moderna e Contemporânea: uma relação atuante nas práticas dos professores. Encontro Nacional de Pesquisa em Educação em Ciências, Campinas.

[8] Rocha, D. M.; Ricardo, E. C. (2014) As crenças de autoeficácia de professores de Física: um instrumento para aferição das crenças de autoeficácia ligadas a Física Moderna e Contemporânea. Caderno Brasileiro de Ensino de Física, v. 31, n. 2. 